\title{
BMPR2 germline mutations in pulmonary hypertension associated with fenfluramine derivatives
}

\author{
M. Humbert*, Z. Deng ${ }^{\#, f}$, G. Simonneau*, R.J. Barst ${ }^{\top}, \S$, O. Sitbon*, M. Wolf ${ }^{+}$, N. Cuervo ${ }^{\#}$, \\ K.J. Moore ${ }^{\#}$, S.E. Hodge ${ }^{\#, f, * *}$, J.A. Knowles ${ }^{\#, f}$, J.H. Morse
}

BMPR2 germline mutations in pulmonary hypertension associated with fenfluramine derivatives. M. Humbert, Z. Deng, G. Simonneau, R.J. Barst, O. Sitbon, M. Wolf, N. Cuervo, K.J. Moore, S.E. Hodge, J.A. Knowles, J.H. Morse. C) ERS Journals Ltd 2002.

ABSTRACT: This study investigated whether patients developing pulmonary arterial hypertension (PAH) after exposure to the appetite suppressants fenfluramine and dexfenfluramine have mutations in the bone morphogenetic protein receptor 2 (BMPR2) gene, as reported in primary pulmonary hypertension.

BMPR2 was examined for mutations in 33 unrelated patients with sporadic PAH, and in two sisters with PAH, all of whom had taken fenfluramine derivatives, as well as in 130 normal controls. The PAH patients also underwent cardiac catheterisation and body mass determinations.

Three BMPR2 mutations predicting changes in the primary structure of the BMPRII protein were found in three of the 33 unrelated patients $(9 \%)$, and a fourth mutation was found in the two sisters. No BMPR2 mutations were identified in the 130 normal controls. This difference in frequency was statistically significant. Moreover, the mutation-positive patients had a somewhat shorter duration of fenfluramine exposure before illness than the mutation-negative patients, a difference that was statistically significant when the two sisters were included in the analysis.

In conclusion, the present authors have detected bone morphogenetic protein receptor 2 mutations that appear to be rare in the general population but may combine with exposure to fenfluramine derivatives to greatly increase the risk of developing severe pulmonary arterial hypertension.

Eur Respir J 2002; 20: 518-523.

\begin{abstract}
*Service de Pneumologie, and ${ }^{+}$Hématologie, Hôpital Antoine Béclère, Clamart, France, and the Depts of Medicine, ${ }^{\$}$ Pediatrics, and ${ }^{\#}$ Psychiatry, Columbia University College of Physicians and Surgeons, ${ }^{f}$ New York State Psychiatric Institute, and $* *$ Division of Biostatistics, Columbia University School of Public Health, New York, NY, USA.

Correspondence: J.H. Morse, Dept of Medicine, Columbia Presbyterian Medical Center, PH 8 East, Suite 101, 630 West 168th Street, New York, NY 10032.

Fax: 2123054943

E-mail: jhm4@columbia.edu
\end{abstract}

Keywords: Anorexigens, bone morphogenetic receptor 2 , fenfluramine, pulmonary hypertension

Received: March 12002

Accepted after revision: May 222002

This study was supported by grants from NIH-HBLI-60056, NIH-DK31813, INSERM, AFM, and Université Paris-Sud. Z. Deng was supported by a PHA fellowship award.
Exposure to appetite suppressants aminorex, fenfluramine and dexfenfluramine are known risk factors for pulmonary arterial hypertension (PAH) [1]. Increased risk for PAH was first reported in the late sixties with exposure to aminorex [2] and in the mid-nineties with fenfluramine or dexfenfluramine [3-5]. However, the exact mechanism(s) by which fenfluramine derivatives promote PAH has not been established [6]. Individual susceptibility factors are likely to play an important role since the absolute risk in the general population is thought to be low. For example, the proportion of individuals developing $\mathrm{PAH}$ among all individuals taking fenfluramine derivatives, has been estimated as $\sim 1$ in 10,000 for overweight individuals exposed to fenfluramine derivatives for $>12$ months [3-5] (S. Rich, Rush Heart Institute Center for Pulmonary Heart Disease, RushPresbyterian-St. Luke's Medical Center, Chicago, IL, USA, personal communication). Presumably this proportion is even lower for individuals who have a shorter exposure to fenfluramine derivatives.

$\mathrm{PAH}$ can occur in individuals who have no known risk factors to develop this condition (primary pulmonary hypertension (PPH)). PPH is a rare condition, with a poor long-term outcome, despite recent therapeutic advances such as continuous intravenous epoprostenol and lung or heart/lung transplantation. Familial PPH (autosomal dominant inheritance with incomplete penetrance) maps to chromosome $2 q 33$ [7, 8]. Mutations of the gene encoding bone morphogenetic receptor II (BMPR-II) were recently identified as the cause of some familial [9-11] and some sporadic PPH [12]. BMPR-II is a cell-surface receptor belonging to the superfamily of receptors for ligands of the transforming growth factor (TGF)- $\beta$ family [13]. The observed missense, nonsense and frameshift mutations coding for BMPR2 were predicted to alter the bone morphogenetic protein and TGF- $\beta 1 /$ SMAD signalling pathways, resulting in proliferation rather than apoptosis of vascular cells [9-14]. In an effort to determine whether BMPR2 mutations are a risk factor for appetite suppressantassociated PAH, the gene was screened in 33 unrelated PAH patients and in two sisters with $\mathrm{PAH}$, all 35 
of whom had a history of fenfluramine or dexfenfluramine exposure, and in 130 normal controls. Both patients and controls were from France.

\section{Methods}

\section{Patient selection}

The study group consisted of $35 \mathrm{PAH}$ patients who had taken the appetite-suppressant drugs fenfluramine, dexfenfluramine or both, and who subsequently developed symptomatic PAH. The study was approved by the Institutional Review Board of Columbia University and by Hôpital Antoine Béclère. The 33 unrelated cases and two affected sisters, referred between 1987 and 2000 for evaluation of pulmonary hypertension, were recruited from the Centre for Pulmonary Vascular Disease, Hôpital Antoine Béclère, France. The first sister was referred to the centre for severe PAH associated with fenfluramine derivatives, and her younger sister was hospitalised 2 yrs later, with the same diagnosis. Patients who had used only amphetamines were excluded, although four patients who used amphetamines concomitant with fenfluramines were included. Evaluation and work-up ruled out all other causes of pulmonary hypertension [1, 15]. The controls consisted of an ethnically matched sample of 130 healthy blood donors collected in the same hospital in France.

\section{Molecular methods}

Genetic variation in both the coding sequence and the intron/exon boundaries of BMPR 2 was assayed by denaturing high performance liquid chromatography

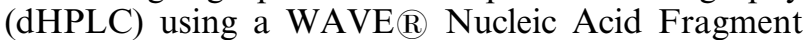
Analysis System (Transgenomics, Inc., Omaha, NE, USA), as per the manufacturer's directions and as described previously [9, 16, 17]. Polymerase chain reaction amplification products ( $\max$ size $=602$ base pairs) were run with up to three melting profiles for fragments with multiple melting domains. In addition, deoxyribonucleic acid (DNA) sequence determination of all fragments (exons 1-13) from each individual, whether or not they contained potential variants, was performed by cycle sequencing using Big Dye ${ }^{\mathrm{TM}}$ terminators (Applied BioSystems (ABI), Inc., Foster City, CA, USA) and sequencing products were resolved and detected with an ABI Model 3100 DNA sequencer $(\mathrm{ABI})$. The resulting DNA sequence traces were analysed using Vector NTI suite 6.0 (Informax Inc., Bethesda, MD, USA), as were the protein sequence alignments.

\section{Statistical methods}

Statistical analyses used Fisher's exact test and the nonparametric Mann-Whitney U-test, as appropriate.

\section{Results}

Thirty-four of the 35 patients were female: 32 White, two Black, and one Indian. Their ages ranged from $18-70 \mathrm{yrs}$, mean age $50 \pm 13$. Their body mass indices ranged 20-40, mean pulmonary artery pressures between $5.3-12.1 \mathrm{kPa}(40-91 \mathrm{mmHg})$, cardiac indices between $1.15-4.28 \mathrm{~L} \cdot \min ^{-1} \cdot \mathrm{m}^{-2}$, and total pulmonary vascular resistance between 559-2504 dynes $\cdot \mathrm{sec} \cdot \mathrm{cm}^{-5}$. Twenty-two patients took dexfenfluramine, 12 fenfluramine, and one used both drugs.

Four BMPR2 mutations that predict changes in the primary structure of the BMPR-II protein were found; three in the 33 unrelated patients (frequency $9 \%$ ), and the fourth in the two sisters. The two sisters with familial BMPR2 mutations did not differ from the remaining patients in the series, in that symptomatic PAH developed only after the use of fenfluramine derivatives. One of the unrelated patients used dexfenfluramine for 5 months and had an $\mathrm{A}$ to $\mathrm{C}$ change in exon 2 at position 246. This DNA sequence change predicts a substitution in the primary amino acid sequence of the receptor from an uncharged glutamine to a positively charged histidine $(\mathrm{Q} 82 \mathrm{H})$ in the extracellular domain that is responsible for ligand binding and dimerisation. The second unrelated patient took fenfluramine for 2 months and had a change from $\mathrm{G}$ to $\mathrm{A}$ in exon 5 at position 545 . This mutation predicts a protein sequence change of an uncharged glycine at position 182 to a negatively charged aspartic acid (G182D) in the kinase domain of the protein. The third unrelated patient took fenfluramine for 1 month and had a $\mathrm{T}$ to $\mathrm{C}$ mutation in exon 11 at position 1447. This mutation predicts a protein sequence change of an uncharged cysteine to a positively charged arginine (C483R). Of interest, the first two mutations change amino acids to ones that are invariant in a few of the other known BMPR-II receptors (figs 1 and 2), whereas the third mutation, involving an evolutionarily conserved amino acid, is

889-Q82H

BMPR-II [Human] BMPR-II [Mus musculus] BMPR-II [Xenopus laevis] BMPR-II [Gallus galus] ActR-II [Homo Sapiens] ActR-II [sheep]

ActR-II [Gallus gallus]

AMHR-II [Homo sapiens] AMHR-II [Rattus norvegicus] TGFR-II [Homo sapiens] TGFR-II [Mus musculus] TGFR-II [Rattus Norvegicus] XSTK3 [Xenopus laevis] Consensus

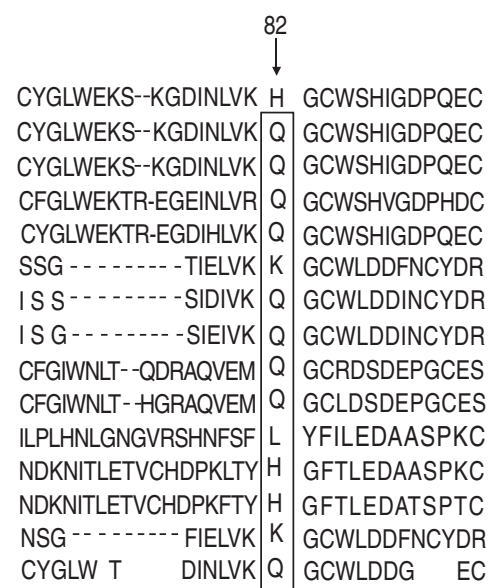

Fig. 1.-Sequence alignment of the type II transforming growth factor (TGF)- $\beta$-superfamily receptors surrounding Q82 in bone morphogenetic protein receptor 2 (BMPR-II). \#889: patient with mutation; Act-R II: activin receptor type II; AMHR-II: antimullerian hormone type II receptor; TGFR-II: TGF- $\beta$ type II receptor; XSTK3: Xenopus activin receptor. 


\begin{tabular}{|c|c|c|c|}
\hline \multicolumn{4}{|c|}{182} \\
\hline 1004-G182D & $---Q$ & D & LHSMNMMEAAAS------EPSLDLDNLKLL \\
\hline BMPR-II [Human] & $--Q$ & G & LHSMNMMEAAAS-----EPSLDLDNLKL \\
\hline BMPR-II [Mus musculus] & $--Q$ & G & LHSMNMMEAAAA -..---EPSLDLDNLKLL \\
\hline BMPR-II [Xenopus laevis] & $---Q$ & G & LHSMNVLEAATS------EPSLDLDNLKLL \\
\hline BMPR-II [Gallus galus] & $--\bar{Q}$ & G & LHSMNMMEAAAS-----EPSLDLDNLKLL \\
\hline AMHR-II [Homo Sapiens] & $--\bar{Y}$ & $\mathrm{R}$ & VRGEPVPEPRPDSGRDWSVELQEIPELCFS \\
\hline AMHR-II [Rattus norvegicus] & $--C$ & $\mathrm{R}$ & VQGGSDPEPEPGSGGDCSEELPELAEIRFS \\
\hline ActR-II [Homo sapiens] & YGHV & D & IH-EDPGPPPPSPLVG-----LKPLQLL \\
\hline ActR-II [sheep] & YPPV & $\mathrm{L}$ & VPTQDPGPPPPSPLG------LKPLQLL \\
\hline ActR-II [Gallus gallus] & YPPV & $\mathrm{L}$ & VPTQDPGPPPPSPLMG------LKPLQLL \\
\hline TGFR-II [Homo sapiens] & SEHC & A & IILEDDRSDISSTCANNINHNTELLPIELD \\
\hline TGFR-II [Mus musculus] & SDNC & A & IILEDDRSDISSTCANNINHNTELLPIELD \\
\hline TGFR-II [Rattus Norvegicus] & SDNC & A & IILEDDRSDISSTCANNINHNTELLPIELD \\
\hline XSTK3 [Xenopus laevis] & YGHV & D & LN-EDPGPTPPSPMVG-----LKPLQLL \\
\hline Consensus & & G & $\begin{array}{llll}S D & E & A S & D L\end{array}$ \\
\hline
\end{tabular}

Fig. 2.-Sequence alignment of the type II transforming growth factor (TGF)- $\beta$-superfamily receptors surrounding G182 in bone morphogenetic protein receptor 2 (BMPR-II). \#1004: patient with mutation; AMHR-II: anti-mullerian hormone type II receptor; ActR-II: activin type II receptor; TGFR-II: TGF- $\beta$ type II receptor; XSTK3: Xenopus activin receptor.

not found in any of the known type-II receptors belonging to the TGF- $\beta$ superfamily. The two affected sisters had a history of 1 and 2 months' dexfenfluramine exposure, respectively, before being diagnosed with PAH. They each had a stop codon $631 \mathrm{C}>\mathrm{T}$, resulting in a nonsense ( $\mathrm{R} 211 \mathrm{X})$ mutation in exon 6 predicted to produce a truncated protein. These mutations were not observed in a sample of 260 ethnically matched chromosomes. The first two of these mutations have not been reported previously [9-12], and identical DNA mutations have been observed for the latter two in sporadic $\mathrm{PPH}$ (C483R) [12] and familial PPH (R211X) [11].

The difference in frequency of mutation between the studied patients and the 130 French controls was statistically significant, whether the two sisters were excluded (comparing 3 out of 33 versus 0 out of 130 , $\mathrm{p}=0.015$, Fisher's exact test, 2-sided), or whether they were counted as a single independent observation ( 4 of 34 versus 0 of $130, \mathrm{p}=0.003$ ). Moreover, none of these changes have been reported in 350 normal chromosomes in the literature [9-12].

The duration of anorexigen use had a median of 1 month in mutation-positive patients (range 1-5 months) and a median of 4 months in the mutation-negative patients (range 1-60 months, with one outlier of 180 months). Eight patients (four mutation-positive and four mutation-negative) had an exposure of $<3$ months.

The patients with a mutated BMPR2 gene had similar clinical and haemodynamic characteristics when compared to the patients with no mutations, except that a shorter duration of exposure to fenfluramine derivatives was found in the patients with BMPR2 mutations. Two analyses were performed, comparing duration of exposure between the mutationpositive patients and the 30 mutation-negative ones: one comparing the durations themselves, and the other comparing the proportion of patients with $<3$ months versus $\geqslant 3$ months exposure. Both analyses yielded statistically significant results if the two sisters were included as independent observations or if they were treated as a single observation with a duration of 1.5 months (table 1).

\section{Discussion}

This study describes the first genetic mutations, namely in BMPR2, detected in individuals displaying PAH after exposure to fenfluramine derivatives. Two of the four mutations found here in the PAH patients with exposure to fenfluramine derivatives are new and have not been reported previously in any disease state [9-12]. The mutations were rare, three mutations in BMPR2 in 33 unrelated patients with sporadic PAH $(9 \%)$ and another mutation in two sisters with familial PAH. Two of the unrelated patients had missense mutations found to be invariant in all vertebrate nonhuman BMPR-type II receptors that have been sequenced, and in the case of the $(\mathrm{Q} 82 \mathrm{H})$ mutation, other members of the TGF- $\beta$ type-II receptor superfamily as well (fig. 1 and 2). The Q82H mutation is also the first noncysteine amino acid substitution to be described in the ligand binding domain of BMPR2 [9-12], however, the mutation does not appear to change the secondary structure of the region. The missense mutation in the third unrelated patient was not found in other BMPR-type II receptors and involved an evolutionally conserved amino acid. Both sisters had the same stop codon mutation and are predicted to produce a truncated protein that may act via the mechanism of haploinsufficiency. Unfortunately, there were no additional samples from family members of the three unrelated cases; therefore it was not possible to determine if the mutations arose de novo. Experiments are in progress to test the physiological implications of these mutations.

Moreover, a short exposure to fenfluramine derivatives may be sufficient to induce or accelerate the progression of the disease in certain BMPR2 mutationpositive individuals. Recently, PAH has been classified

Table 1.-p-Values (two-sided) for analyses comparing duration of exposure between mutation-positive and mutationnegative patients

$\begin{array}{cc}\begin{array}{c}\text { Excluding } \\ \text { both sisters }\end{array} & \begin{array}{c}\text { Combining the } \\ \text { sisters into } \\ \text { one observation }\end{array}\end{array}$

one observation

\begin{tabular}{|c|c|c|c|}
\hline $\begin{array}{l}\text { Comparing durations } \# \\
\text { Comparing proportions of } \\
\text { patients with duration } \\
<3 \text { months versus } \geqslant 3 \text { months }\end{array}$ & $>0.05$ & 0.032 & 0.012 \\
\hline
\end{tabular}

0.032

0.021

Including both sisters as independent observations

\footnotetext{
\#: Mann-Whitney U-test; ${ }^{\bullet}$ : Fisher's exact test.
} 
into unexplained pulmonary hypertension, or PPH and $\mathrm{PAH}$ of certain known aetiologies such as collagen vascular diseases, human immunodeficiency virus infection, portal hypertension, congenital systemic to pulmonary shunts and anorexigen exposure [1]. The finding of BMPR2 mutations in anorexigeninduced PAH adds this predisposition to pulmonary vascular disease to that originally found in $\mathrm{PPH}$ [9-12], suggesting that gene mutations might provide a better classification of PAH.

The International Primary Pulmonary Hypertension Study found an association between appetite suppressants and $\mathrm{PPH}$, with odds ratio (relative risk estimates) of 6.3 (95\% confidence interval (CI) 3.0 $13.2) ; 90 \%$ of cases for whom a defined product could be traced had used a fenfluramine derivative [3]. The risk increased markedly with duration of use (relative risk estimate of 23.1 for $>3$ months, 95\% CI 6.9-77.7) [3]. However, some patients developed severe PAH even with short-term use of fenfluramine, emphasising the relevance of individual susceptibility to fenfluramines [3, 18]. Similarly, the patients with BMPR2 mutations studied here appeared to have a shorter duration of exposure to fenfluramine derivatives when compared to patients without evidence of mutations.

Several unknowns prohibit a more thorough evaluation of the $9 \%$ frequency of BMPR 2 mutations in PAH after fenfluramine derivatives observed here. First, the methods used here could have missed large deletions of BMPR2, and mutations in the promoter and large introns were not screened. Second, the frequency of BMPR2 mutations in the general population is unknown (however, based on the present authors' observation of no new BMPR2 mutations in 610 control chromosomes (the 260 normal chromosomes studied, plus the literature [9-12], plus another 350 French chromosomes determined here) the present authors can form an exact one-sided $95 \%$ CI of $0-0.0049$, i.e. an upper $95 \%$ confidence limit of $\sim 1 / 200$ for allele frequency, or $\sim 0.01$ for carrier frequency, although the present authors surmise that the actual frequency is well below this (see Appendix)). Third, the penetrances of these mutations are unknown and may vary. The age of onset of disease both within families and between subjects carrying identical but recurrent mutations is variable. The previously reported large number of individuals nonpenetrant for the disease phenotype points to the potential requirement for additional factors, either environmental or genetic in the pathogenesis of the disease. Fourth, the distinction between sporadic and familial PPH can be hard to discern, as illustrated by the two sisters. The first sister was classified as having sporadic anorexigen associated PPH until the second sister developed the same disease. Unfortunately, the present study was unable to obtain additional family members from any of the BMPR 2 mutation-positive individuals. In the sporadic cases this would help to determine if the observed mutations are de novo and in the family the observation of an individual with the mutation with no exposure to fenfluramine derivatives and no PAH would support the hypothesis that exposure is increasing the penetrance of these mutations. A greater understanding of the effects of appetite suppressant exposure in BMPR2 mutants will require an examination of a much larger sample of human chromosomes to determine their frequencies and the construction of transgenic animals with mutations for use in models of appetite suppressantinduced PAH.

The findings of the present study suggest there are additional mechanisms triggering the occurrence of the disease. Firstly, fenfluramines and aminorex inhibit potassium current flux in pulmonary vascular smooth muscle and may therefore stimulate pulmonary vasoconstriction [19]. Secondly, it has been speculated that patients who develop pulmonary hypertension while taking an anorectic agent could have a pre-existing diminished nitric oxide activity [20]. Such a defect has been demonstrated in a small series of patients displaying fenfluramine-associated PAH [20]. Thirdly, poor metabolisers of fenfluramine derivatives may have a more pronounced exposure to the drug and could be more prone to develop the condition [21]. Lastly, drug-induced alteration of the serotonin pathway might promote the occurrence of PAH [22, 23]. By interacting with the serotonin transporter, fenfluramine derivatives release serotonin from platelets and inhibit its reuptake into platelets and pulmonary endothelial cells [22]. As a consequence, the whole blood serotonin concentration increases with fenfluramine treatment [23]. Serotonin is known to be a powerful pulmonary vasoconstrictor and can induce platelet aggregation [24]. Moreover, serotonin is a growth factor for pulmonary smooth muscle cells [25]. The possible relevance of the serotonin hypothesis in fenfluramine-induced PAH is supported by the fact that a decrease in platelet serotonin storage with enhanced blood concentration of free serotonin has been reported in sporadic cases of $\mathrm{PPH}$, and fenfluramine derivatives induce valvular heart disease very similar to carcinoid syndrome [26-28].

Further investigations should determine whether abnormal transforming growth factor- $\beta$ signalling alone, or in combination with other factors, plays a role in the occurrence of pulmonary hypertension associated with fenfluramine derivatives. However, it is becoming more apparent that the pathogenesis of pulmonary arterial hypertension is complex [29] and may sometimes require two hits, genetic and/or environmental, as has been found for neoplasia [30]. The mutations detected in bone morphogenetic protein receptor 2 in the present study may be among the genetic "hits" needed to develop severe pulmonary arterial hypertension, particularly in combination with exposure to fenfluramine derivatives.

\section{Appendix}

To determine population carrier frequency $(x)$ directly, one would have to test large numbers of control individuals for BMPR2 mutations, an expensive task. However, there is also an indirect approach that can estimate the lower bound of this frequency that can be used in the absence of a large amount of data: it can be shown that

$$
z \times p=x \times P e n
$$


where $z$ is defined as the proportion of individuals who develop PAH, among all individuals taking fenfluramine derivatives; $p$ is the proportion of mutation carriers, among affected individuals who were exposed to fenfluramine derivatives; and Pen (penetrance) is defined as the risk of developing PAH for individuals who carry one of the mutations and who have been exposed to appetite suppressants. (Mathematical details are not shown but are available from Dr. Hodge upon request.) The authors have an estimate of $p=3 / 33=0.091$ from the present study's data (not including the two sisters). It is known that Pen cannot $>1.0$, but actually, the authors anticipate it may be $<0.3$. Thus, if, for example, $z$ were known to be 1 in 10,000 (see text), then carrier frequency $x$ would have to equal at least $0.0000091=1 / 110,000$ (based on Pen $=100 \%$ ), but could be as high as $1 / 22,000$ or $1 / 11,000$, if Pen were as low as $20 \%$ or $10 \%$. Thus, it could be helpful to future investigators of PAH if a more precise estimate of $z$ could be determined.

Acknowledgements. The authors are indebted to S. Rich, for aiding their understanding of the risk of pulmonary arterial hypertension in those taking fenfluramine derivatives and to $\mathrm{Y}$. Enson for his cogent suggestions.

\section{References}

1. Rich S. Primary pulmonary hypertension: executive summary from the World Symposium-primary pulmonary hypertension 1998. Available from the World Health Organization via the Internet. www.who.int/ncd/ cvd/.pph.html. Date last accessed: November 82000.

2. Gurtner HP. Pulmonary hypertension, plexogenic pulmonary arteriopathy and the appetite suppressant drug aminorex: post or propter? Bull Eur Physiopath Resp 1979; 15: 897-923.

3. Abenhaim L, Moride Y, Brenot F, et al. Appetitesuppressant drugs and the risk of primary pulmonary hypertension. N Engl J Med 1996; 335: 609-616.

4. Rich S, Rubin L, Walker AM, Schneeweiss S, Abenhaim L. Anorexigens and pulmonary hypertension in the United States: Results from the surveillance of North American pulmonary hypertension. Chest 2000; 117: 870-874.

5. Abenhaim L, Rich S, Benichou J, Begaud B. Letter to Editor. New Engl J Med 1997; 336: 512-513.

6. Simonneau G, Fartoukh M, Sitbon O, Humbert M, Jagot J-L, Hervé P. Primary pulmonary hypertension associated with the use of fenfluramine derivatives. Chest 1998; 114: 195S-198S.

7. Morse JH, Jones AC, Barst RJ, Hodge SE, Wilhelmsen $\mathrm{KC}$, Nygaard TG. Mapping of familial primary pulmonary hypertension locus (PPH1) to chromosome 2q31-q32. Circulation 1997; 95: 2603-2606.

8. Nichols WC, Koller DL, Slovis B, et al. Localization of the gene for familial primary pulmonary hypertension to chromosome 2q31-32. Nat Genet 1997; 15: 277-280.

9. Deng Z, Morse JH, Slager SL, et al. Familial primary pulmonary hypertension (gene PPH1) is caused by mutations in the bone morphogenetic protein receptor-II gene. Am J Hum Genet 2000; 67: 737-744.

10. The International PPH Consortium, Lane KB,
Machado RD, Pauciulo MW, et al. Heterozygous germline mutations in a TGF- $\beta$ receptor, BMPR 2 , are the cause of familial primary pulmonary hypertension. Nat Genet 2000; 26: 81-84.

11. Machado RD, Pauciulo MW, Thomson JR, et al. BMPR2 haploinsufficiency as the inherited molecular mechanism for primary pulmonary hypertension. $\mathrm{Am}$ J Hum Genet 2001; 68: 92-102.

12. Thomson JR, Machado RD, Pauciulo MW, et al. Sporadic primary pulmonary hypertension is associated with germline mutations of the gene encoding BMPR-II, a receptor member of the TGF- $\beta$ family. J Med Gen 2000; 37: 741-745.

13. Massagué J, Chen YG. Controlling TGF- $\beta$ signaling. Genes Dev 2000; 14: 627-644.

14. Morrell NW, Yang X, Upton PD, et al. Altered growth responses of pulmonary artery smooth muscle cells from patients with primary pulmonary hypertension to transforming growth factor-beta (1) and bone morphogenetic proteins. Circulation 2001; 104: 790-795.

15. Rubin LJ. Primary pulmonary hypertension. Chest 1993; 104: 236-250.

16. Underhill PA, Jin L, Lin AA, et al. Detection of numerous $\mathrm{Y}$ chromosome biallelic polymorphisms by denaturing high-performance liquid chromatography. Genome Res 1997; 7: 996-1005.

17. O'Donovan MC, Oefner PJ, Roberts SC, et al. Blind analysis of denaturing high-performance liquid chromatography as a tool for mutation detection. Genomics 1998; 52: 44-49.

18. Mark EJ, Patalas ED, Chang HT, Evans RJ, Kessler SC. Fatal pulmonary hypertension associated with short-term use of fenfluramine and phentermine. N Engl J Med 1997; 337: 602-606.

19. Weir EK, Reeve HL, Huang JMC, et al. Anorexic agents aminorex, fenfluramine, and dexfenfluramine inhibit potassium current in rat pulmonary vascular smooth muscle and cause pulmonary vasoconstriction. Circulation 1996; 94: 2216-2220.

20. Archer SL, Djaballah K, Humbert M, et al. Nitric oxide deficiency in fenfluramine- and dexfenfluramineinduced pulmonary hypertension. Am J Respir Crit Care Med 1998; 158: 1061-1067.

21. Higenbottam T, Humbert M, Simonneau G, et al. Subjects deficient for CYP2D6 expression (poor metabolisers) are over-represented among patients with anorectic associated pulmonary hypertension (abstract). Am J Respir Crit Care Med 1999; 159: A165.

22. McTavish D, Heel RC. Dexfenfluramine, a review of its pharmacological properties and therapeutic potential in obesity. Drugs 1992; 43: 713-733.

23. Martin F, Artigas F. Simultaneous effects of p-chloroamphetamine, d-fenfluramine, and reserpine on free and stored 5-hydroxytryptamine in brain and blood. J Neurochem 1992; 59: 1138-1144.

24. Egermayer P, Town GI, Peacock AJ. Role of serotonin in the pathogenesis of acute and chronic pulmonary hypertension. Thorax 1999; 54: 161-168.

25. Fanburg BL, Lee SL. A new role for an old molecule: serotonin as a mitogen. Am J Physiol 1997; 16: L795L806.

26. Connolly HM, Crary JL, McGoon MD, et al. Valvular heart disease associated with fenfluraminephentermine. N Engl J Med 1997; 337: 581-588.

27. Robiolo PA, Rigolin VH, Wilson JS, et al. Carcinoid heart disease: correlation of high serotonin levels with 
valvular abnormalities detected by cardiac catheterization and echocardiography. Circulation 1995; 92: 790-795.

28. Hervé P, Launay J-M, Scrobohaci M-L, et al. Increased plasma serotonin in primary pulmonary hypertension. Am J Med 1995; 99: 249-254.

29. Archer S, Rich S. Primary pulmonary hypertension: a vascular biology and translational research "work in progress". Circulation 2000; 102: 2781-2791.

30. Yeager ME, Halley GR, Golpon HA, Voelkel NF, Tuder RM. Microsatellite instability of endothelial cell growth and apoptosis genes within plexiform lesions in primary pulmonary hypertension. Circ Res 2001; 88: e2-e11. 